\title{
A Case of Organizing Pneumonia Induced by Tocilizumab
}

\author{
Kayoko Ikegawa, Masayuki Hanaoka, Atsuhito Ushiki, Hiroshi Yamamoto and Keishi Kubo
}

\begin{abstract}
A 66-year-old woman rheumatoid arthritis was treated with methotrexate and tocilizumab. Chest radiography revealed bilateral consolidation of an upper lesion in the lung. Laboratory data indicated a hepatic disorder and increased eosinophils. Transbronchial lung biopsy specimens showed organizing pneumonia. Infection was unfavorable based on culture and PCR. Drug lymphocyte stimulation test showed positive results both for methotrexate and tocilizumab. We were concerned that her pneumonitis was drug-induced. And the symptoms appeared after the infusion of tocilizumab. Here, we report a case of tocilizumab-induced organizing pneumonia.
\end{abstract}

Key words: tocilizumab, drug-induced pneumonia, organizing pneumonia

(Intern Med 50: 2191-2193, 2011)

(DOI: 10.2169/internalmedicine.50.5497)

\section{Introduction}

Tocilizumab is the first humanized interleukin (IL)-6 receptor-inhibiting monoclonal antibody. IL-6 is a cytokine involved in the inflammatory and immunologic responses characteristic of various autoimmune diseases. Clinical trial data have shown the effect of tocilizumab in the moderation of severe rheumatoid patients failing anti-rheumatic drugs (DMARDs) and anti-TNF agents (1). We describe a case of drug-induced organizing pneumonia caused by tocilizumab.

\section{Case Report}

A 64-year-old Japanese woman diagnosed with rheumatoid arthritis (RA) in 2008 by a rheumatologist at another hospital was started on methotrexate. In the second week of June 2010, tocilizumab treatment was started. Three days later, general fatigue appeared and patient was admitted to that hospital. At the time of admission, cough and sputum were not present. Laboratory data showed hepatic disorder and an increased level of eosinophils (Table 1A). Chest radiography revealed bilateral consolidation of an upper lesion in the lung (Fig. 1A). Chest computed tomography (CT) showed consolidation with air bronchogram in both upper lobes, and the right lung was slightly contracted (Fig. 1B). The rheumatologist suspected that the patient had drug- induced pneumonia and hepatic disorder, so he discontinued both drugs. At the end of June, the patient was admitted to our hospital.

Upon admission to our hospital, the patient's vital signs were as follows: pulse rate 90, blood pressure 126/73, and temperature $36.5^{\circ} \mathrm{C}$. No rales were audible in either lung fields. Laboratory data showed that her hepatic disorder had improved and the eosinophil percentage had decreased (Table 1B). Arterial blood gas at room air revealed a little hypoxemia (pH 7.43, $\mathrm{PaO}_{2} 75.7$ Torr, $\mathrm{PaCO}_{2} 40.6$ Torr). Chest radiography revealed consolidation in both upper lungs, but it was decreased compared to two weeks prior (Fig. 1C). Antibiotics were not used at the first hospital. So the shadow was improved by only discontinuation of tocilizumab. Pulmonary function test showed a normal pattern $(\% \mathrm{FVC}=85.7 \%$, FEV1.0\%=88.6\% $)$.

On the fourth day after admission, fiberoptic bronchoscopy was performed. Shadows were revealed in the upper lobe, therefore we did not perform bronchoalveolar lavage. We performed a transbronchial lung biopsy, culture, and PCR of the transbronchial washing. The transbronchial biopsy specimens showed organizing pneumonia (Fig. 2). The culture of the transbronchial washing was negative. PCR specific for Pneumocystis jirovecii, Aspergillus, Tubercle bacillus, and Mycobacterium avium in the transbronchial washes were negative. The cytology of bronchial washing was class I. A drug lymphocyte stimulation test (DLST) 
Table 1. Laboratory Data upon Admission to the First Hospital (A) and Our Hospital (B)

\begin{tabular}{|c|c|}
\hline (A) & (B) \\
\hline Hematology & Hematology \\
\hline WBC $9100 / \mathrm{mm}^{3}$ & WBC $8950 / \mathrm{mm}^{3}$ \\
\hline Neu $76.2 \%$ & Neu $77.3 \%$ \\
\hline Lym $\quad 11.4 \%$ & Lym $12 \%$ \\
\hline Eos $10.1 \%$ & Eos $4.7 \%$ \\
\hline $\mathrm{Hb} \quad 11.0 \mathrm{~g} / \mathrm{dL}$ & $\mathrm{Hb} \quad 11.0 \mathrm{~g} / \mathrm{dL}$ \\
\hline Plt $\quad 57.1 \times 10^{4} / \mathrm{mm}^{3}$ & Plt $\quad 41 \times 10^{4} / \mathrm{mm}^{3}$ \\
\hline Biochemistry & Biochemistry \\
\hline AST $152 \mathrm{IU} / \mathrm{L}$ & AST $26 \mathrm{IU} / \mathrm{L}$ \\
\hline ALT $163 \mathrm{IU} / \mathrm{L}$ & ALT $50 \mathrm{IU} / \mathrm{L}$ \\
\hline $\begin{array}{r}\text { LDH } 298 \text { IU/L } \\
(114-220 \mathrm{IU} / \mathrm{I})\end{array}$ & $\begin{array}{l}\mathrm{LDH} \quad 186 \mathrm{IU} / \mathrm{L} \\
\text { YGTP } 72 \mathrm{IU} / \mathrm{L}\end{array}$ \\
\hline ALP $423 \mathrm{IU} / \mathrm{L}$ & ALP $329 \mathrm{IU} / \mathrm{L}$ \\
\hline (124-367 IU/L) & T.Bil $0.44 \mathrm{mg} / \mathrm{dL}$ \\
\hline Serology & Serology \\
\hline CRP $1.5 \mathrm{mg} / \mathrm{dL}$ & CRP $\quad 0.28 \mathrm{mg} / \mathrm{dL}$ \\
\hline & $\begin{array}{l}\mathrm{KL}-6 \quad 232 \mathrm{mg} / \mathrm{dL} \\
\quad(105-435 \mathrm{mg} / \mathrm{dL})\end{array}$ \\
\hline & $\begin{array}{l}\text { SP-D } 42.5 \mathrm{ng} / \mathrm{mL} \\
(0-110 \mathrm{ng} / \mathrm{mL})\end{array}$ \\
\hline & $\begin{array}{l}\text { RF } 96 \mathrm{IU} / \mathrm{L} \\
(0-10 \mathrm{IU} / \mathrm{L})\end{array}$ \\
\hline & $\begin{array}{r}\text { MMP-3 } 367 \mathrm{ng} / \mathrm{mL} \\
\quad(17.3-59.7 \mathrm{ng} / \mathrm{mL})\end{array}$ \\
\hline
\end{tabular}

Abbreviations: KL-6, Krebs von den Lungen-6; SP-D, surfactant protein-D; RF, rheumatoid factor; MMP-3, matrix metalloproteinase-3

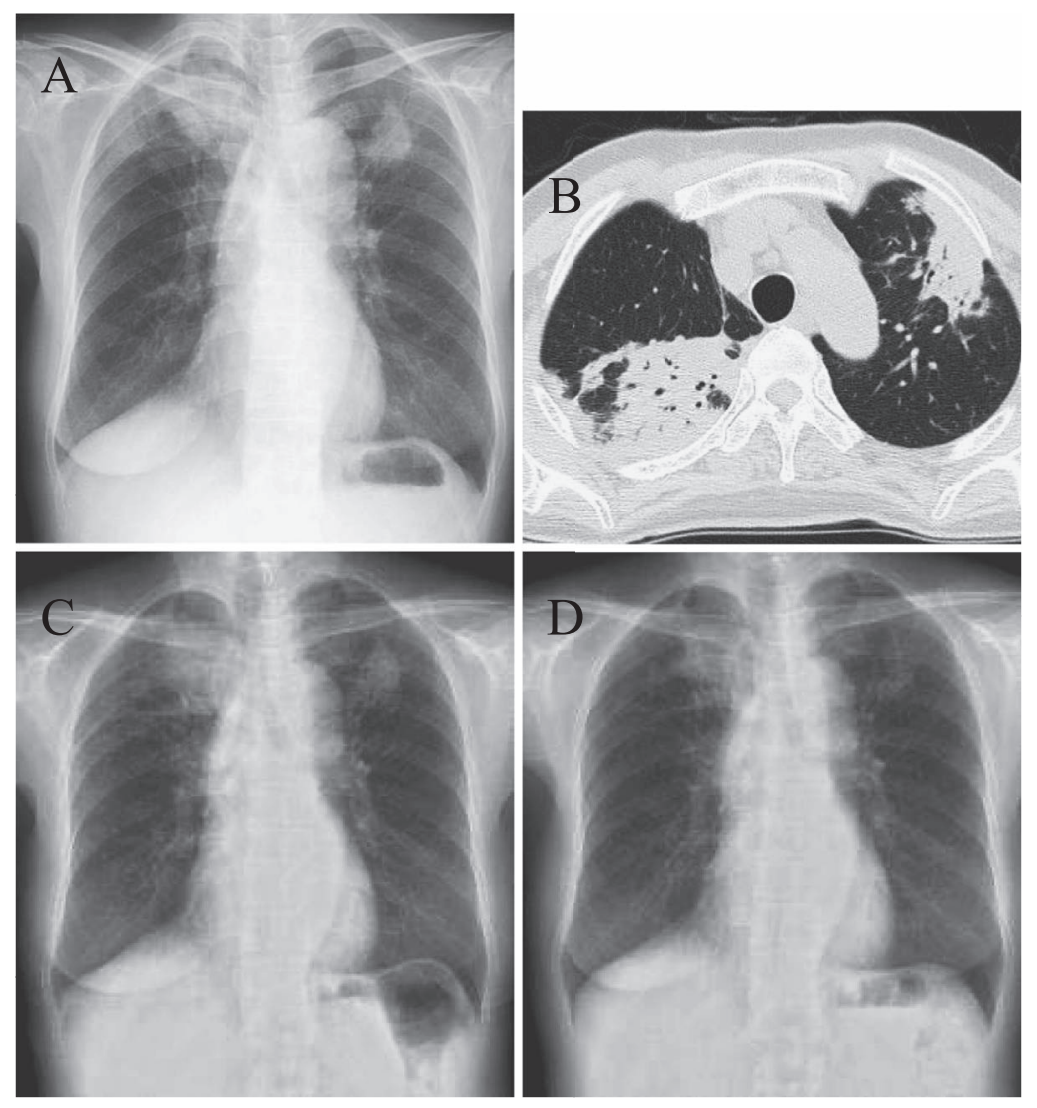

Figure 1. (A) Chest radiography upon admission to the first hospital showed bilateral consolidation of an upper lesion in the lung. (B) Chest CT scan showed consolidation with air bronchogram in both upper lobes. The right lung was slightly contracted. (C) Chest radiography upon admission to our hospital showed decreased consolidation. (D) Chest radiography was improved at discharge. 


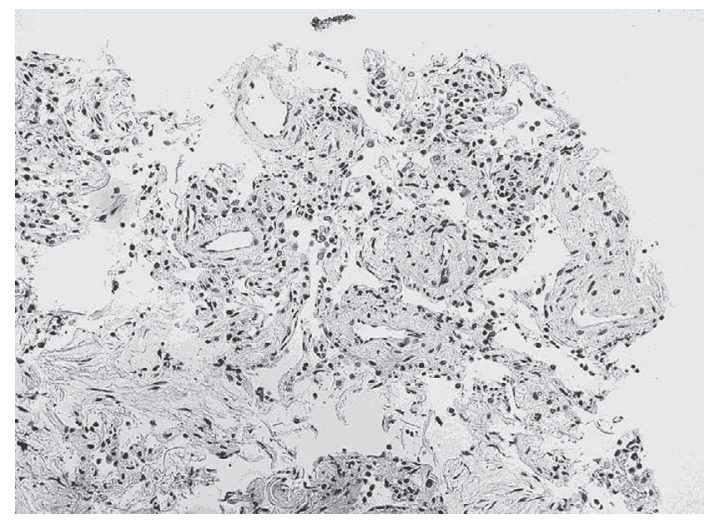

Figure 2. Transbronchial lung biopsy specimens. Polypoid masses of granulation tissue fill the lumens of respiratory alveolar ducts. Adjacent alveolar interstices are broadened by a lymphoplasmacytic inflammatory infiltrate. Hematoxylin and Eosin staining $(\times 200)$.

showed positive results for both methotrexate (stimulating index 952\%) and tocilizumab (stimulating index 444\%).

The patient's symptoms appeared three days after infusion with tocilizumab and infection was defined. We considered that the organizing pneumonia was induced by tocilizumab. As stopping the drugs improved the results of chest radiography and laboratory values, we determined that steroids were not needed. But her RA was exacerbated by stopping the therapy. The pain in her knee became worse and CRP increased. On the 12th day after admission, we started methylprednisolone infusion $(250 \mathrm{mg} /$ day $)$ for three days and continued an intake of $20 \mathrm{mg} /$ day prednisolone. After the treatment, her pain and chest radiography were improved (Fig. 1D). The patient was discharged 21 days after admission.

\section{Discussion}

We reported a case of organizing pneumonia induced by tocilizumab in a patient with RA. In this case, she was treated with methotrexate and tocilizumab, but the possibility that her organizing pneumonia was due to tocilizumab was higher, because she was taking methotrexate for two years before the symptoms appeared, which was just after infusion with tocilizumab, and it was accompanied by an abnormal liver function test.
The DLST for methotrexate and tocilizumab were both positive, but the false-positive rate of the DLST for methotrexate is high $(2,3)$. Therefore, the DLST for methotrexate in RA patients is nonspecific.

Tocilizumab is a new drug for RA therapy. In the phase II study of 623 patients with RA (tocilizumab $8 \mathrm{mg} / \mathrm{kg} \mathrm{n}=205$, $4 \mathrm{mg} / \mathrm{kg} \mathrm{n}=214$; placebo $\mathrm{n}=204$ ), the most common adverse event was upper respiratory tract infection and increases in mean hepatic aminotransferase concentrations were frequent. The most common serious adverse events were infections or infestations, such as bacterial pneumonia, Pneumocystis jirovecii pneumonia, cellulitis, and peridiverticular abscess. Interstitial lung disease occurred in one patient who received $4 \mathrm{mg} / \mathrm{kg}$ tocilizumab, and pulmonary fibrosis occurred in one patient who received $8 \mathrm{mg} / \mathrm{kg}$ tocilizumab. The subjects recovered rapidly on appropriate therapy and one of them continued tocilizumab treatment (4).

Tocilizumab-induced pneumonia is not frequent. To the best of our knowledge, this is the first report of tocilizumabinduced pneumonia. During tocilizumab use, the risk of infection becomes higher (5). If chest radiography shows an abnormal appearance during tocilizumab use, denying the possibility of infection is necessary. If infection is denied, tocilizumab-induced pneumonia should be considered.

The authors state that they have no Conflict of Interest (COI).

\section{References}

1. Hushaw LL, Sawaqed R, Swies G, et al. Critical appraisal of tocilizumab in the treatment of moderate to severe rheumatoid arthritis. Ther Clinical Risk Manag 6: 143-152, 2010.

2. Hagiwaraz K, Sato T, Hirokazu Y, et al. LST for methotrexate in patients with rheumatoid arthritis. Allergy Clin Immunol Int: J World Allergy Org 17: 156-161, 2005.

3. Hirata S, Hattori N, Kumagai K, Haruta Y, Yokoyama A, Kohno N. Lymphocyte transformation test is not helpful for the diagnosis of methotrexate-induced pneumonitis in patients with rheumatoid arthritis. Clin Chim Acta 407: 25-29, 2009.

4. Smolen JS, Beaulieu A, Rubbert-Roth A, et al. Effect of interleukin-6 receptor inhibition with tocilizumab in patients with rheumatoid arthritis (OPTION study): a double-blind, placebocontrolled, randomized trial. Lancet 371: 987-997, 2008.

5. Campbell L, Chen C, Bhagat SS, Parker RA, Östör AJ. Risk of adverse events including serious infections in rheumatoid arthritis patients treated with tocilizumab: a systematic literature review and meta-analysis of randomized controlled trails. Rheumatology (Oxford) 50: 552-562, 2010.

(C) 2011 The Japanese Society of Internal Medicine http://www.naika.or.jp/imindex.html 